\title{
Application of response surface methodology in process optimization of Soytofu and their sensory evaluation
}

\author{
Deepa Saini $^{1}$, CS Chopra ${ }^{2}$ and Sabbu Sangeeta ${ }^{3}$
}

Received: 14 April 2021 / Accepted: 21 June 2021 / Published online: 31 October 2021

(C) Indian Dairy Association (India) 2021

\begin{abstract}
The objective of this investigation was to optimize the levels of four salt and three acid coagulants and coagulating temperature of soy milk so as to prepare quality soytofu by employing Response Surface Methodology (RSM) and to select an ideal one among the seven coagulants. To optimize the level of coagulant and temperature, Three Level Factorial Design was used. This included three levels of salt $(0.2,0.4$ and $0.6 \%$, w/v on soy milk basis) and acid $(0.15,0.25$ and $0.35 \%$, w/v on soy milk basis) coagulants with three levels of coagulating temperature $\left(75,82.5\right.$ and $\left.90^{\circ} \mathrm{C}\right)$. Thus $13 \mathrm{RSM}$ experiments including five central and eight axial points were conducted to produce soytofu samples with each of the coagulant. Soytofu samples were evaluated organoleptically on nine point hedonic rating scale. Results revealed that the optimum concentration of coagulants $\left(\% \mathrm{w} / \mathrm{v}\right.$, on soymilk basis) and coagulating temperature $\left({ }^{\circ} \mathrm{C}\right)$ of soymilk for making quality soytofu was $0.6,86.55,0.57,84.9,0.6$, $87.23,0.46,86.18,0.35,89.33,0.3,80.25$ and $0.15 \%, 87.45^{\circ} \mathrm{C}$, respectively, for $\mathrm{CaCl}_{2}, \mathrm{CaSO}_{4}, \mathrm{MgCl}_{2}, \mathrm{MgSO}_{4}$, lactic acid, acetic acid and citric acid coagulants. Preparation of soytofu sample from RSM optimized level and their organoleptic evaluation indicated that among the seven coagulants calcium chloride was best for making quality soytofu and it contained 68.59, 50.3, 12,
\end{abstract}

\footnotetext{
${ }^{123}$ Department of Food Science and Technology, GB Pant University of Agriculture and Technology, Pantnagar-263145, Uttarakhand, India

Deepa Saini $(\bowtie)$

Department of Food Science and Technology, GB Pant University of Agriculture and Technology, Pantnagar-263145, Uttarakhand, India Email:deepasainipantnagar@gmail.com
}

5.9 and $15.35 \%$ moisture, protein, crude fat, ash and carbohydrates, respectively.

Keywords: Coagulants, Optimization, Soybean, Soytofu, Temperature

\section{Introduction}

Tofu is usually considered as salt or acid coagulated water based gel, with soy lipids and proteins trapped in the gel network (Kohyama et al. 1995). It is an inexpensive, nutritious and versatile meat or cheese substitute with bland taste and porous texture. On the moisture free basis, tofu contains about $50 \%$ protein and $27 \%$ oil, and the remaining constituents are carbohydrates and minerals (Tripathi and Mishra, 2005). Yield and quality of tofu are important parameters which should be kept in mind during the production of tofu. It is influenced by environmental as well as processing factors such as cultivar (Sun and Breene, 1991, Tanwar et. 1998, Krishna et al. 2002), soaking time (Choi and Kim 1983), type of coagulant (Sutar et al. 2009, Shokunbi et al. 2011), concentration of coagulant (Sun and Breene, 1991), temperature of coagulant (Shih et al. 1997, Agrahar-Murugkar 2015), pressure applied (Gandhi and Bourne 1988) and processing methods (Agrahar-Murugkar 2015).

Till now many coagulants have been used in soytofu preparation like calcium chloride, calcium sulphate, magnesium chloride, lemon juice, Epsom salt and top water of fermented maize (Sun and Breene 1991, Obtalu 2008, Sutar et al. 2009, Shokunbi et al. 2011). There is dearth of information regarding usage of acid coagulants (citric acid, acetic acid and lactic acid). So, in present investigation response surface methodology (RSM) was applied to optimize the level of coagulants and coagulating temperature of seven different alt and acid coagulants. As, RSM is a valuable statistical tool that has been widely used in process optimization as well as in recipe formulation and processing conditions (Sharma et al. 2005, Deshpande et al. 2008, Karuppaiya et al. 2009 and Granato et al. 2010). 


\section{Materials and Methods}

The present investigation was carried out in the Department of Food Science and Technology, G.B. Pant University of Agriculture and Technology, Pantnagar, U.S. Nagar (Uttrarakhand). Mature variety of soybean PS-1347 was procured from Crop Research Centre of G.B. Pant University of Agriculture and Technology, Pantnagar. Soybean seeds were cleaned manually and stored in a cool and dry place until required. Seven coagulants (calcium chloride, calcium sulphate, magnesium chloride, magnesium sulphate, lactic acid, acetic acid and citric acid), and other chemicals employed in the present study were of AR grade. The physiochemical properties of soybean seeds were also analyzed.

\section{Physico-chemical analysis of soybean}

Soybean used in research was test for various physical parameters such as thousand grain weight, hull content, hardness, bulk density, true density and porosity as per the following formula:

$$
\text { Bulk density }(\mathrm{g} / \mathrm{cc})=\frac{\text { Weight of soybean in gram }}{\text { Volume of soybean in cubic centimeter }}
$$

Weight of grain in gram

True density $(\mathrm{g} / \mathrm{cc})=$

Volume of toluene displaced in cubic centimeter

$$
\text { Per cent porosity }=\frac{\text { True density }- \text { Bulk density }}{\text { True density }} \times 100
$$

Hardness of 10 randomly taken seeds of soybean was determined with a Hardness Tester (Kiya Seisakusho Ltd., Japan). Hardness represented the force required to break the seed vertically and horizontally and average value was expressed in $\mathrm{kg}$. While moisture, fat, protein, total ash, calcium, phosphorus and iron was estimated by Ranganna (1996).

\section{Design of experiment}

The investigation comprised of two experiments. In the first experiment, seven coagulants were employed individually for preparation of soytofu. Soymilk was coagulated at three different concentration of each coagulant. Thirteen soytofu samples were prepared with each coagulant by using RSM and level of each coagulant and coagulating temperature were optimized so as to produce soytofu having maximum yield and ideal organoleptic characteristics. In the second experiment, seven soytofu samples were prepared as per the RSM optimized levels for each of the coagulant and corresponding coagulating temperature. These soytofu samples were subjected to organoleptic evaluation so as to find out the best coagulant among the seven and proximate composition of the best soytofu sample was also determined. The experiments were planned using RSM with Three Level Factorial Design. A full second order model was fitted into each response. The adequacy of the model was tested using coefficient of determination $\left(\mathrm{R}^{2}\right)$ and Fisher's F-test.

\section{Preparation protocol}

Whole soybeans were immersed in water (14-16 hours) and were washed thoroughly by rubbing them manually between the palms, the hulls were removed completely. Then dehulled soybeans were then ground at a Mixer-Grinder (Philips, HL 1632) in hot water $\left(95^{\circ} \mathrm{C}\right)$ for $3 \mathrm{~min}$. During extraction the ratio (bean to water) was $1: 8(\mathrm{w} / \mathrm{v})$. The resultant suspension was passed through a doublelayered fabric of muslin. The soymilk thus obtained was boiled to inactivate trypsin inhibitor and other anti-nutritional factors for five minutes (Sutar et al. 2009).

The volume of coagulant needed as per the RSM was dissolved in $20 \mathrm{ml}$ of distilled water and transferred to a 1 liter size stainless steel tank. Freshly prepared $500 \mathrm{ml}$ of soymilk was brought to the coagulating temperature required and then gently poured into the vessel containing coagulant for soytofu preparation. Then for about 30 minutes the contents were left undisturbed and allowed to cool to room temperature. The content was passed through a double layered cheese cloth to separate curd and whey. The curd was then transferred into a wooden box lined with a double layered cheese cloth. Cloth corners were folded over the contents and a constant pressure of $28 \mathrm{~g} / \mathrm{cm}^{2}$ was exerted for 15 minutes on the contents. The box had holes to drain off the whey at its sides and the edges. The prepared soytofu was then removed from the wooden box and weighed and stored in chilled water at refrigeration temperature until organoleptic analysis. Freshly prepared samples of soytofu were tested organoleptically within 24 hours (Table 1).

\section{Screening of ideal coagulant}

For the screening of best coagulants, seven soytofu samples were prepared from each coagulant separately as per the RSM optimized coagulant concentration and corresponding coagulating temperature. An ideal coagulant was selected on the basis of yield and sensory parameters. A soytofu sample was prepared as per the ideal selected coagulant and it was analyzed for proximate composition (moisture, crude protein, crude fat, ash and carbohydrate) as per AOAC methods.

\section{Organoleptic evaluation}

The acceptability of soytofu samples prepared from soybean variety PS 1347 was determined organoleptically. The taste panel was comprised of 10 members drawn from staff and PG-students of Department of Food Science and Technology. The panelists evaluated soytofu samples on 9-point hedonic scale for sensory 
attributes (appearance, colour, odour, taste, texture and overall acceptability).

\section{Statistical analysis}

Optimization of levels of each coagulant and coagulating temperature was done using the RSM (Design-Expert 8.0.7.1). Data recorded in the experiments were analyzed and the response functions were developed using the multiple regression. ANOVA was used to analyze the models as described by Snedecor and Cochran (1986).

\section{Results and Discussion}

The physico-chemical characteristics of soybean variety PS-1347 are shown in table 2. Similar values with regard to fat content in soybean were also observed by Krishna et al. (2003). The value of ash content in whole soybean was in accordance with those reported by Sutar et al. (2009). The carbohydrate content is slightly lower than reported by Sutar et al. (2010). Jain and Mittal (1992) and Krishna et al. (2003) also estimated calcium in different Indian varieties of soybeans which ranged from 62.38 to $298.47,252.91$ to $304.17 \mathrm{mg} / 100 \mathrm{~g}$, respectively.

\section{Effects of different levels of salt coagulants and temperature on yield and sensory profile of soytofu}

Soytofu prepared by $0.6 \% \mathrm{CaCl}_{2}$ was added to soymilk at $82.5^{\circ} \mathrm{C}$ had maximum product yield of $27.9 \%$ while addition of $0.2 \% \mathrm{CaCl}_{2}$ in soymilk at $90^{\circ} \mathrm{C}$ resulted in minimum soytofu yield of $22.4 \%$. Soytofu yield was maximum (29\%) when $\mathrm{CaSO}_{4}$ was used at a level of $0.4 \%$ while the coagulating temperature of soymilk was $82.5^{\circ} \mathrm{C}$. Results indicate that yield of soytofu was maximum when $0.6 \% \mathrm{MgCl}_{2}$ was used at $75^{\circ} \mathrm{C}$. An observation of yield by coagulation through lactic acid $\left(0.6 \%, 82.5^{\circ} \mathrm{C}\right)$, acetic acid $(0.35 \%$, $\left.75^{\circ} \mathrm{C}\right)$ and citric acid $\left(0.35 \%, 90^{\circ} \mathrm{C}\right)$ was noted as $27.5 \%, 25.7 \%$ and $22 \%$, respectively. The sensory score of the prepared soytofu was done on the basis of nine-point of hedonic scale. Maximum overall acceptability score of soytofu at different coagulant and temperature levels were $\mathrm{CaCl}_{2}(8.75) \mathrm{CaSO}_{4}(8.25) \mathrm{MgCl}_{2}(9) \mathrm{MgSO}_{4}$ (9) lactic acid (9), acetic acid (8.87) and citric acid (9). Yield was calculated by following formula

$$
\text { Yield }(\%)=\frac{\text { Soytofu obtained }}{\text { Soymilk taken for coagulation }} \times 100
$$

Calculated F values of soytofu yield based on ANOVA depicted that yield is significantly affected by the level of coagulant and temperaure at $1 \%$ level of significance when coagulated by $\mathrm{CaCl}_{2}$ and $\mathrm{MgCl}_{2}$, while in case of citric acid and lactic acid yield is only affected by coagulant concentration at $1 \%$ level of significance. Product yield was affected by temperature at $1 \%$ and $5 \%$ level of significance when coagulant was $\mathrm{MgSO}_{4}$ and $\mathrm{CaSO}_{4}$, respectively but at $5 \%$ level of significance soytofu yield was affected by using only acetic acid.

When $\mathrm{CaCl}_{2}$ was used at $0.6 \%$ concentration with temperature of soymilk as $82.5^{\circ} \mathrm{C}$, the sensory parameters (odour, taste and texture) was maximum as compare to other combination of processing variables, while appearance of soytofu had highest score at $0.4 \%$ level of $\mathrm{CaCl}_{2}$ and $82.5^{\circ} \mathrm{C}$. The $\mathrm{F}$ value suggests that the effect on appearance and taste are significant at $5 \%$ level with values of 5.63 and 5.74, respectively, odour texture and overall acceptability are significant at $1 \%$ level with values 12.05 , 20.35 and 27.44, respectively. However effect on the color of soytofu is nonsignificant with $\mathrm{F}$ value of 2.44

It can be seen that soytofu produced by $0.6 \% \mathrm{CaSO}_{4}$ with coagulating temperature of $82.5^{\circ} \mathrm{C}$ of milk was rated superior (overall acceptability score 8.25 ). The ratings of this soytofu sample with regard to odour (8.5), taste (8.5) and texture (8) were also appreciably higher. The effect on colour of soytofu due to

Table 1 Response Surface experiments to prepare soytofu by employing salt and acid coagulants

\begin{tabular}{llllllc}
\hline Experiment & \multicolumn{2}{l}{ Salt coagulant } & \multicolumn{2}{l}{ Acid coagulant } & \multicolumn{2}{l}{ Coagulating temperature } \\
\cline { 2 - 6 } & $\%$ & coded value & $\%$ & coded value & ${ }^{\circ} \mathrm{C}$ & coded value \\
\hline 1 & 0.2 & -1 & 0.15 & -1 & 75 & -1 \\
2 & 0.6 & +1 & 0.35 & +1 & 82.5 & 0 \\
3 & 0.4 & 0 & 0.25 & 0 & 82.5 & 0 \\
4 & 0.2 & -1 & 0.15 & -1 & 90 & +1 \\
5 & 0.6 & +1 & 0.35 & +1 & 75 & -1 \\
6 & 0.4 & 0 & 0.25 & 0 & 75 & -1 \\
7 & 0.6 & +1 & 0.35 & +1 & 90 & +1 \\
8 & 0.4 & 0 & 0.25 & 0 & 82.5 & 0 \\
9 & 0.2 & -1 & 0.15 & -1 & 82.5 & 0 \\
10 & 0.4 & 0 & 0.25 & 0 & 82.5 & 0 \\
11 & 0.4 & 0 & 0.25 & 0 & 82.5 & 0 \\
12 & 0.4 & 0 & 0.25 & 0 & 90 & 0 \\
13 & 0.4 & 0 & 0.25 & 0 & 82.5 & +1
\end{tabular}


Table 2 Physico-chemical characteristics of soybean seeds

\begin{tabular}{lc}
\hline Physical characters & Values \\
\hline Hull content $(\%)$ & $7.98 \pm 0.289^{*}$ \\
Grain hardness (kg) & $8.75 \pm 0.238$ \\
& $19.1 \pm 0.185$ \\
Bulk density (g/cc) & $0.71 \pm 0.004$ \\
True density (g/cc) & $1.21 \pm 0.079$ \\
\% Porosity & $43.63 \pm 0.312$ \\
Colour & Light yellow \\
1000 grain weight (g) & $132.03 \pm 0.026$ \\
Moisture (\%) & $10.3 \pm 0.395$ \\
Protein $(\%)$ & $39.98 \pm 0.036$ \\
Crude fat (\%) & $19.55 \pm 0.195$ \\
Ash (\%) & $6.23 \pm 0.193$ \\
Carbohydrate (by difference) $(\%)$ & 23.94 \\
Calcium (mg) & $257 \pm 1.155$ \\
Phosphorus (mg) & $421.72 \pm 1.938$ \\
Iron (mg) & $11.18 \pm 0.068$ \\
\hline
\end{tabular}

*Average value \pm Standard Deviation

processing variables was negligible. The ratings for odour, taste, texture and overall acceptability of soytofu increased due to increasing level of $\mathrm{CaSO}_{4}$ from 0.2 to $0.6 \%$ irrespective of temperature level while appearance of the product is improved when soymilk was coagulated at 75 and $82.5^{\circ} \mathrm{C}$ temperature.

Soytofu prepared using $0.4 \% \mathrm{MgCl}_{2}$ and $90^{\circ \mathrm{C}}$ temperature of soymilk recorded highest ratings for its appearance (9), odour (8.5), taste (8.75) and texture (9). In general, soytofu sample produced with $0.2 \%$ coagulant at $75^{\circ} \mathrm{C}$ was disliked most as indicated by its lowest organpleptic score with regard to appearance (4), taste (5.25), texture (4.25) and overall acceptability (4.5). The $F$ value suggests that the effect on appearance odour, taste and overall acceptability are significant at $1 \%$ level with values of $27.74,77,11.3$ and 11.64 , respectively while texture is significant at $5 \%$ level with $\mathrm{F}$ value of 6.51 . However, color is not affected significantly. The $\mathrm{R}^{2}$ values were found to be $95.26,97.88$, $88.86,82.31,89.09 \%$ for appearance, odour, taste, texture and overall acceptability, respectively while it was was $58.6 \%$ for color which further indicate that color was not influenced significantly due to variations in concentrations of $\mathrm{MgCl}_{2}(0.2-$ $0.6 \%)$ and temperature $\left(75-90^{\circ} \mathrm{C}\right)$ as employed in making soytofu. Ratings for appearance, taste and texture of the product are improved due to either increasing the concentration of $\mathrm{MgCl}_{2}$ or temperature and both were independent of each other. Rating of odour is maximum with the use of $0.4 \% \mathrm{MgCl}_{2}$. The odour of soytofu is improved with increasing the coagulating temperature of soymilk and use of $\mathrm{MgCl}_{2}$ at the level of 0.4 and $0.6 \%$.

With the use of $0.4 \% \mathrm{MgSO}_{4}$ and temperature of soymilk as $90^{\circ} \mathrm{C}$ registered maximum organoleptic ratings with regard to appearance (8.5), odour (8.75), taste (8.75) and texture (9). Improvement in odour, texture and overall acceptability of the
Table 3 Optimum values of coagulant concentration and temperature of soymilk to produce ideal soy soytofu

\begin{tabular}{llc}
\hline Coagulants & Coagulant concentration (\%) & $\begin{array}{l}\text { Temperature of } \\
\text { soymilk }\left({ }^{\circ} \mathrm{C}\right)\end{array}$ \\
\hline $\mathrm{CaCl}_{2}$ & 0.6 & 86.55 \\
$\mathrm{CaSO}_{4}$ & 0.57 & 84.9 \\
$\mathrm{MgCl}_{2}$ & 0.6 & 87.23 \\
$\mathrm{MgSO}_{4}$ & 0.46 & 86.18 \\
Lactic Acid & 0.35 & 89.33 \\
Acetic Acid & 0.3 & 80.25 \\
Citric Acid & 0.15 & 87.45 \\
\hline
\end{tabular}

product due to increasing the coagulating temperature of soymilk at all the levels of $\mathrm{MgSO}_{4}(0.2$ to $0.6 \%)$ were used in the preparation of soytofu. The appearance score of soytofu is maximum at $82.5^{\circ} \mathrm{C}$ temperature of soymilk and that is independent of concentration of $\mathrm{MgSO}_{4}$. However, variations in temperature with any of the concentration of $\mathrm{MgSO}_{4}$ were not affecting the taste of the soytofu.

Data indicate that overall acceptability score of the soytofu sample by lactic acid was maximum (9). Furthermore, ratings for the other sensory attributes i.e. odour, taste and texture were also highest (9,9 and 8.85, respectively) for this soytofu sample. Soytofu produced with use of $0.25 \%$ lactic acid and temperature of soymilk as $82.5^{\circ} \mathrm{C}$ was of poorest sensory value due to its least overall acceptability score of 3 . The model $F$ value suggests that the effect on appearance, odour and taste was significant at $1 \%$ level with values of 54.1,37.7 and 13.33, respectively while texture and overall acceptability, was significant at 5\% level with values 6.05 , and 6.49 , respectively. The $\mathrm{R}^{2}$ values were found to be 97.51 , $96.33,90.87,81.19$ and $82.22 \%$ for appearance, odour, taste, texture and overall acceptability, respectively while it was $43.38 \%$ for color which further indicate that color was not influenced significantly due to variations in concentration of lactic acid ( 0.15 $0.35 \%)$ and temperature of soymilk $\left(75-90^{\circ} \mathrm{C}\right)$ as used in making soytofu. Lack of Fit for the significantly influenced sensory attributes (appearance, odour, taste, texture and overall acceptability) was non significant.

Organoleptic ratings in respect of appearance, odour, taste, texture and overall acceptability were 8.75, 8.88, 9, 9 and 8.75, respectively for soytofu sample wherein acetic acid concentration and soymilk temperature were $0.25 \%$ and $82.5^{\circ} \mathrm{C}$, respectively. By regression analysis model $\mathrm{F}$ value suggests that the effect on appearance, odour, taste, texture and overall acceptability are highly significant at $1 \%$ level with values of $80,153,19.29,15$ and 15.9 , respectively. The $\mathrm{R}^{2}$ values were found to be $98.35,99.15$, $93.03,91.52$ and $92 \%$ for appearance, odour, taste, texture and overall acceptability, respectively while it was was $72.11 \%$ for color which indicate that color was not influenced significantly due to variations in concentration of acetic acid $(0.15-0.35 \%)$ and temperature of soymilk $\left(75-90^{\circ} \mathrm{C}\right)$ as used in making soytofu. Lack 


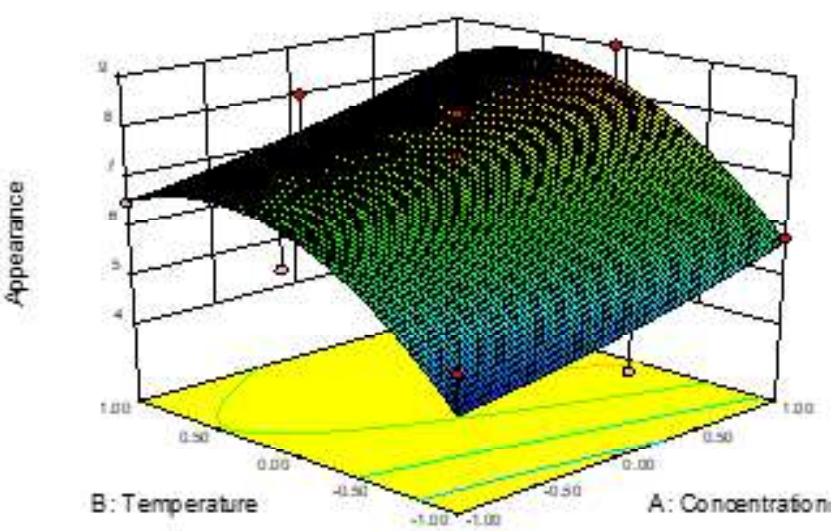

Fig.1. Response surface plot of appearance score of tofu prepared by calcium chloride

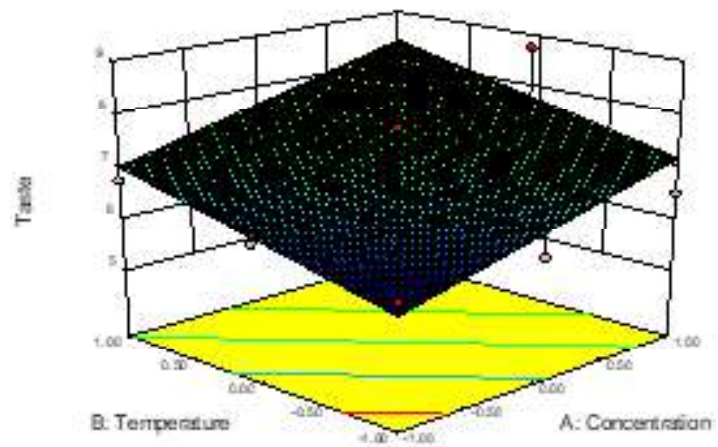

Fig. 3. Response surface plot of taste score of tofu prepared by calcium chloride

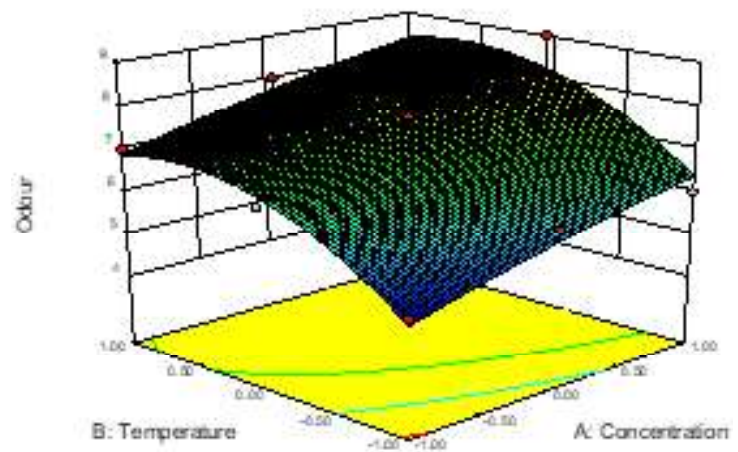

Fig.2. Response surface plot of odour score of tofu prepared by calcium chloride

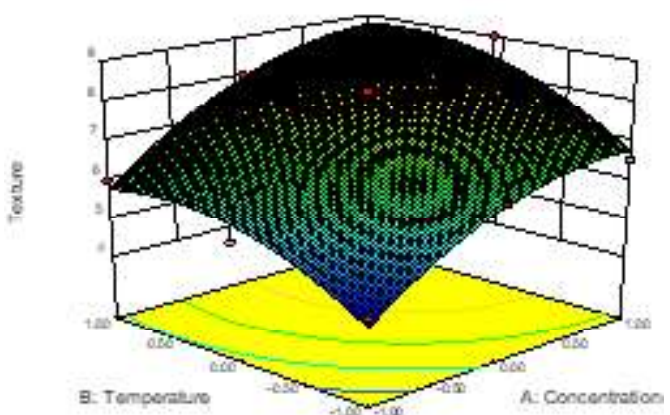

Fig. 4. Response surface plot of texture score of tofu prepared by calcium chloride

Table 4 Yield and organoleptic score of soytofu prepared using seven coagulants at optimized levels of coagulant concentration and temperature of soymilk

\begin{tabular}{|c|c|c|c|c|c|c|c|}
\hline \multirow[t]{2}{*}{ Responses } & \multicolumn{6}{|c|}{ Coagulants } & \multirow[b]{2}{*}{ Citric Acid } \\
\hline & $\mathrm{CaCl}_{2}$ & $\mathrm{CaSO}_{4}$ & $\mathrm{MgCl}_{2}$ & $\mathrm{MgSO}_{4}$ & Lactic Acid & Acetic Acid & \\
\hline Yield $(\%)$ & 27 & 27.02 & 25.78 & 26.91 & 25 & 21.93 & 20 \\
\hline Appearance & 8.71 & 7.29 & 8.29 & 7.86 & 7.29 & 6.14 & 6.14 \\
\hline Odour & 8.57 & 7.8 & 7.29 & 7.3 & 6.57 & 4.86 & 7.86 \\
\hline Taste & 8.72 & 7.57 & 7.86 & 7.11 & 7.57 & 5.43 & 5.43 \\
\hline F-value & $* *$ & $* *$ & $* *$ & $* *$ & $* *$ & $* *$ & $* *$ \\
\hline S.Em \pm & - & 0.35 & 0.43 & 1.64 & 0.19 & 0.55 & 0.48 \\
\hline CD at $1 \%$ & - & 0.85 & 0.95 & 1.85 & 0.60 & 1.0 & 1.0 \\
\hline
\end{tabular}

** Significant at $1 \%$ level of significance

of Fit for the significantly influenced sensory attributes (appearance, odour, taste, texture and overall acceptability) was non significant.

Soytofu occupied first position with regard to overall acceptability score (9) at $0.15 \%$ citric acid at $82.5^{\circ} \mathrm{C}$. The ratings for appearance, taste and texture in respect of this sample was highest (9). The model $\mathrm{F}$ value suggests that the effect on appearance, odour, taste, texture and overall acceptability are highly significant at $1 \%$ level with values of 9.42, 7.61, 16.81, 9.91 and 9.58 , respectively. The $\mathrm{R}^{2}$ values were found to be 87.22 , $84.46,92.29,87.63$ and $87.21 \%$ for appearance, odour, taste, texture and overall acceptability, respectively while it was $31.26 \%$ for color which further indicate that color was not influenced 
significantly due to variations in concentration of citric acid $(0.15$ $0.35 \%)$ and temperature of soymilk $\left(75-90^{\circ} \mathrm{C}\right)$ as used in making soytofu. Ratings for appearance, taste, texture and overall acceptability declined with increase in concentration of citric acid at any of three coagulating temperatures used in the study. Odour score is unaffected due to variations in the levels of citric acid at all the three levels of temperature. Texture and odour of the soytofu sample are improved with increase in temperature of soy milk and variations in the concentration of coagulant used. Increase in coagulating temperature of soy milk does not affect the score of appearance at all the three concentrations of citric acid.

Variations in yield and sensory attributes of soytofu prepared by coagulating soymilk at different temperature with different types of coagulants might be ascribed to nature of coagulating agent and their variable mode of formation of soy gel. Two types of coagulants as employed in this investigation for formation of soytofu were salt type and acid type. Formation of protein gel due to addition of salt in soymilk depend upon ionic strength, water affinity, molecular weight, molecular size, ionization ability of forming cross linkage etc. of coagulants. Similarly, formation of protein gel by incorporation of different acid coagulants is governed by type of acid and their $\mathrm{pH}$ lowering effect. Gel strength is influenced by coagulating temperature, type of coagulants and its concentration. Softness or compactness of gel is affected by coagulants water binding or water trapping property of gel which inturn control the yield as well as sensory properties of gel. Several previous researches have also recognized different factors which affect the yield and sensory quality of soy soytofu. Gandhi (2009), Sun and Breene (1991), Shih et al. (1997), Choi et al. (1983), Lim et al. (1990), Sun and Breene (1991), Yuwono (2013), Shih et al. (1997), Gandhi and Bourne (1988), reported that yield of soy soytofu depends upon soybean variety, processing method, soaking time, type of and concentration of coagulants, temperature of soymilk for coagulation, stirring speeds and time of coagulation and pressing of curd, respectively. Similarly, Narayan et al. (1997), Tanwar et al. (1998), Yuwono (2013), Li et al. (2014), Smith et al. (1960) and Wang (1967) also bring into being that soybean variety, storage condition of soybean, method of production, type and concentration of coagulant and pressing of soytofu affect the sensory profile of soytofu.

\section{Yield and sensory evaluation of soytofu prepared by optimized levels of coagulants and temperature of soymilk}

Yield and organoleptic score of soytofu prepared using selected coagulants at optimized levels shows that use of calcium sulphate and calcium chloride as coagulant gave maximum yield 27.02 and $27 \%$, respectively as compared to other coagulants. Soymilk coagulated with citric acid produced minimum yield $(20 \%)$ of soytofu. Krishna et al. (2002) also observed similar results of calcium chloride in preparation of soytofu (Table 4).
Soytofu was evaluated by the panelists to determine its acceptability. It was evaluated for appearance, colour, odour, taste, texture and overall acceptability on nine-point hedonic scale. Soytofu prepared from calcium chloride at concentration of $0.6 \%$ and $86.55^{\circ} \mathrm{C}$ temperature of soymilk gives highest scores for appearance, colour, odour, taste, texture and overall acceptability with values $8.71,9,8.57,8.72,8.71$ and 8.73 , respectively. Statistical analysis of the data showed significant difference at $1 \%$ level among the soytofu samples prepared from different coagulants. Soytofu prepared from calcium chloride was found to be most satisfactory as it had utmost overall acceptability(Fig.1-4). This was followed by magnesium sulphate, magnesium chloride and lactic acid. Previous researches reported that soytofu prepared with calcium salts had very superior general acceptability in terms of colour, texture, taste and overall acceptability (Table 4).

Soytofu prepared by using $\mathrm{CaCl}_{2}$ as a coagulant was found to be finest for making soytofu. The moisture, protein, crude fat, ash and carbohydrate content of soytofu were recorded as $68.59 \pm$ $0.02,50.3 \pm 0.302,12 \pm 0.120,5.9 \pm 0.911$ and $15.35 \pm 0.03 \%$, respectively. Shokunbi et al. (2011) also determined proximate composition of soytofu which were slightly higher than present investigation. The ash content reported in this work $(5.9 \%)$ is slightly higher than reported by Shih et al. (1997). Such variations can be attributed to the variation in preparation methods as well as the types of soybean used to produce soytofu. However, Obiegbuna et al. (2014) recorded lower values for proximate composition of soytofu.

\section{Conclusions}

On the basis of above observations it can be concluded that the concentration of coagulants and levels of coagulating temperature of soymilk were different for making ideal soytofu. The optimized levels of coagulants and coagulating temperature for making quality soytofu was $0.6,86.55,0.57,84.9,0.6,87.23$, $0.46,86.18,0.46,0.35,89.33,0.3,80.25$ and $0.15 \%, 87.45^{\circ} \mathrm{C}$, respectively for $\mathrm{CaCl}_{2}, \mathrm{CaSO}_{4}, \mathrm{MgCl}_{2}, \mathrm{MgSO}_{4}$, lactic acid, acetic acid and citric acid coagulants. Preparation of soytofu sample from RSM optimized level and their organoleptic evaluation indicated that among the seven coagulants calcium chloride was best for making quality soytofu with higher and it contained $68.59,50.3,12,5.9$ and $15.35 \%$ moisture, protein, crude fat, ash and carbohydrates, respectively.

\section{References}

Agrahar-Murugkar D (2015) Effect of different process parameters on the quality of soymilk and soytofu from sprouted soybean. J Food Sci Technol 52: 2886-2893

Choi KS, Kim SH (1983) Effect of soaking time on sugar content and yield of soytofu. J Korean Soc Food Nutr 12: 401-406

Deshpande RP, Chinnan MS, McWatters KH (2008) Optimization of a chocolate-flavoured, peanut-soy beverage using response surface 
methodology (RSM) as applied to consumer acceptability data. Food Sci. Technol-LEB 41: 1485-1492

Gandhi AP (2009) Quality of soybean and its food products. Int Food Res J 16: 11-19

Gandhi AP (2000) Soymilk potential supplement for dairy milk. Indian Foods Indus 19: 392-397

Gandhi AP, Bourne MC (1988) Effect of pressure and storage time on texture profile parameters of soybean curd (soytofu). J Texture Stud 19: $137-142$

Golbitz P 1995. Traditional soyfoods: Processing and products. J Nutr 125: 570-572

Granato D, Ribeiro JCB, Castro IA, Masson ML (2010) Sensory evaluation and physicochemical optimisation of soy-based desserts using response surface methodology. Food Chem 121: 899-906

Jacson CJC, Dini JP, Lavandier C, Rupasinghe HPV, Faulkner H, Poysa V (2002) Effects of processing on the content and composition of isoflavones during the manufacturing of soy beverage and soytofu. Process Biochem 37: 117-1123

Jain A, Mittal BK (1992) Quality characterstic of paneer prepared from different varieties of soybean. J Food Sci Technol 27: 298-300

Kamizake NKK, Silva LCP, Prudencio SH (2016) Effect of soybean aging on the quality of soymilk, firmness of soytofu and optimum coagulant concentration. Food Chem 190: 90-96

Karuppaiya M, Sasikumar E, Viruthagiri T, Vijayagopal V (2009) Optimization of process parameters using Response Surface Methodology (RSM) for ethanol production from waste cashew apple juice using Zymomonasmobilis. Chem Eng Commun 196: 1433 $-1443$

Khoshoo TN (1995) Census of India's biodiversity, tasks ahead. Curr Sci 69: $14-17$

Kohyama K, Sano Y, Doi E (1995) Rheological characterteristics and gelation mechanism of tofu (Soybean curd). J Agric Food Chem 43: $1800-1812$

Krishna A, Singh G, Aggarwal K (2002) Evaluation of different soybean varieties for the preparation of soytofu. Beverage and Food World. February: 43-44

Krishna A, Singh G, Kumar D, Aggarwal K (2003) Physico-chemical characteristics of some new varieties of soybean. J Food Sci Technol 40: 490-492

Li M, Chen F, Yang B, Lai S, Yang H, Liu K, Bu G, Fu C, Deng Y (2014) Preparation of organic soytofu using organic compatible magnesium chloride incorporated with polysaccharide coagulants. Food Chem 167: $68-174$

Lim BT, DeMan JM, DeMan L, Buzzell RI (1990) Yield and quality of soytofu as affected by soybean and soymilk characteristics. Calciumsulphate coagulant. J Food Sci 55: 1088-1092

Narayan R, Chauhan GS, Verma NS (1988) Changes in the quality of soybean during storage. Part 1-Effect of storage on some physicochemical properties of soybean. Food Chem 27: 13-23

Obatolu VA (2008) Effect of different coagulants on yield and quality of tofu from soymilk. European Food Res Technol 226: 467-472

Obiegbuna JE, Morah GN, Ishiwu CN (2014) Comparison of yields and physicochemical properties of lime juice with acetic acid and calcium chloride coagulated soybean curds. J Food Nutr Sci 2: 58-62

Poysa V, Woodrow L, Yu K (2006) Effect of soy protein subunit composition on soytofu quality. Food Res Int 39: 309-317

Ravishankar M (2016) Vegetable soybean: a crop with immense potential to improve human nutrition and diversify cropping systems in Eastern India- a Review. Soybean Res 14: 01-13

Sharma AK, Sarkar BC, Sharma HK (2005) Optimization of enzymatic process parameters for increased juice yield from carrot using response surface methodology. Eur Food Res Technology 221: 106112
Shih MC, Hou HJ, Chang KC (1997) Process optimization for soft soytofu. J Food Sci 62: 833-837

Shokunbi OS, Babajide OO, Otaigbe DO, Tayo GO (2011) Effect of coagulants on the yield, nutrient and anti-nutrientcomposition of soytofu. Arch Appl Sci Res 3: 522-527

Singh RJ, Hymowitz T (1999) Soybean genetic resources and crop improvement. Genome 42: 605-616

Smith AK, Watanabe T, Nash AM (1960) Soytofu from Japanease and United States soybean. Food Tech 14: 332-336

Snedecor GW and Cochran WG (1986) Statistical Methods. 7th Edition, Iowa State University Press, Ames, 90

Sun N, Breene WM (1991) Calcium sulphate concentration influence on yield and quality of soytofu from five soybean varieties. J Food Sci 56:1604-1607

Sutar N, Sutar PP and Singh G (2009) Evaluation of Different Soybean Varieties for Manufacture of Soy Ice-cream. Int J Dairy Technol 63: 136-142

Tanwar VK, Mital BK, Tayagi SM, Singh N (1998) Studies on physicochemical, textural and sensory attributes of soytofu prepared using salt and acid coagulants. Beverage and Food World May 24: 18-19

Tripathi AK, Mishra AK (2005) Soybean- a consummate functional food: A review. J Food Sci and Technol. 42: 111-119

Wang HL (1967) Products from soybeans. Laboratory preparations of soytofu. Food Tech 21: 799-800

Yuwono SS (2013) The use of fermented whey as a coagulant in soytofu industries. J Agrc Sci Technol 3: 807-183 